\title{
Study on distribution characteristics of brominated flame retardants in sediments
}

\author{
Tae-Seung Kim, Sun-Kyoung Shin, Jung-Keun $\mathrm{Oh}^{1}$ and Jong-Eun Park ${ }^{2}$ ^ \\ National Institute of Environmental Research, Environmental Research Complex, \\ Kyung-seo-dong, Seo-gu, Incheon 404-708, Korea \\ ${ }^{1}$ Graduate School of Environment and Information Sciences, Yokohama National University, Yokohama, Japan \\ ${ }^{2}$ Department of Environmental Engineering, Jeonbuk National University, Jeonju 561-756, Korea \\ (Received July 5, 2012; Revised July 27, 2012; Accepted July 27, 2012)
}

\section{퇴적물 중 브롬화난연제 농도분포 특성에 관한 연구

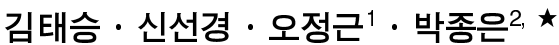

국립환경과학원, ${ }^{1}$ 요코하마대학 대학원 환경정보학부, ${ }^{2}$ 전북대학교 환경공학과

(2012. 7. 5. 접수, 2012. 7. 27. 수정, 2012. 7. 27. 승인)

\begin{abstract}
Total 11 samples of sediments from the Geum river and the Nakdong river and its estuaries were analyzed to investigate the distribution characteristics of PBDEs and HBCD. Concentration of PBDEs in sediments ranged from 2.19 101.34 (average 30.70, median 20.91) ng/g-dw. The concentration range of PBDEs in river sediments is greater than those of estuary sediments. The HBCD concentration was ranged from N.D. 7.85 (average 1.47, median 0.32) $\mathrm{ng} / \mathrm{g}-\mathrm{dw}$. HBCD concentrations compared with PBDEs are approximately $1 / 20$ level, which is associated with low domestic usage. Isomer patterns of PBDEs and HBCD suggested that not only the use of commercial products, but the physicochemical properties of these materials, environmental degradation, and environmental behavior could affect the distribution characteristics of these chemicals and their isomers.

요 약: 본 연구에서는 퇴적물 중 브롬화난연제의 잔류농도 분포특성을 파악하기 위해 금강과 낙동강 수 계 및 하구언에서 총 11 개 시료를 대상으로 $\mathrm{PBDEs}$ 와 $\mathrm{HBCD}$ 를 분석하였다. $\mathrm{PBDEs}$ 의 총 농도 검출범위 는 2.19 101.34 ng/g-dw, 평균농도는 30.70 (중앙값 20.91) ng/g-dw로 나타났으며 하천이 하구언에 비해 농도변화가 큰 것으로 나타났다. HBCD 농도범위는 N.D. 7.85 ng/g-dw, 평균농도는 1.47 (중앙값 0.34) $\mathrm{ng} / \mathrm{g}-\mathrm{dw}$ 로 나타났다. $\mathrm{HBCD}$ 농도는 PBDEs에 비해 약 $1 / 20$ 정도 낮은 범위로서 이는 국내에서 사용된 브롬화 난연제 중 $\mathrm{HBCD}$ 사용량이 상대적으로 적었기 때문인 것으로 판단된다. $\mathrm{PBDEs}$ 와 $\mathrm{HBCD}$ 의 이 성체 분포를 확인한 결과, 상업용 제품사용에 의한 유출과 같은 직접적인 원인 외에도 이들 물질의 물리 화학적 성질과 광학적 분해 및 환경 중 거동 특성 등이 복합적으로 작용하여 분포패턴에 영향을 미치는 것으로 판단되었다.
\end{abstract}

Key words: BFRs, PBDEs, HBCD, sediment, distribution

Corresponding author

Phone : +82-(0)63-270-2448 Fax : +82-(0)63-270-2449

E-mail : envipje@jbnu.ac.kr 


\section{1. 서 론}

브롬화난연제(Brominated flame retardants; BFRs)는 플라스틱, 건축자재, 가전제품 및 섬유제품 등 가연성 물질의 화재 위험성을 줄이기 위해 다양한 산업분야 에서 광범위하게 사용된 화학물질이다. 이들 중 Polybrominated diphenylethers (PBDEs)와 Hexabromocyclododecane $(\mathrm{HBCD})$ 는 대표적인 브롬화난연제 물질로 서 생물 농축성과 생식이상 및 간독성을 유발시키는 내분비계 장애물질로 분류되고 있으며 ${ }^{1-2}$ 환경 및 인 체오염 사례는 1980 년대부터 선진국에서 보고되기 시 작하였다. ${ }^{3-5}$

브롬화난연제의 경제성과 산업적 장점에도 불구하 고 이들 물질에 의한 독성 및 안전성에 대한 문제로 인해 2009년 스톡홀름협약 제4차 당사국회의에서는 일부 PBDEs가 신규 POPs로 확정되었으며 $\mathrm{HBCD}$ 에 대해서도 지정여부가 재검토되고 있는 실정이다. 미국 에서는 2004년 말부터 Penta-BDE와 Octa-BDE의 사 용을 자발적으로 중지하였으며 Deca-BDE는 생산, 수 입 및 사용을 2012년까지 단계적으로 중지하고, 2013 년에는 전면 중지할 것을 발표하였다. 우리나라도 2006년부터 penta-, octa-BDEs를 취급제한물질로 지정 하고 제조, 수입, 사용 등을 금지하였다. $\mathrm{HBCD}$ 는 2003년 EU 기술회의에서 환경에 대한 유해한 물질이 며 수생생물에 매우 독성이 강한 물질로 분류되었다.

$\mathrm{PBDEs}$ 와 $\mathrm{HBCD}$ 등 브롬화난연제 물질은 산업시설 을 비롯하여 가정 생활용품 등 발생원이 매우 다양한 특성을 가지고 있다. 이들 발생원으로부터 환경 중으 로 배출된 후 환경매체로 이동하면서 하천수나 강우 유출 등을 통하여 최종적으로 퇴적물에 축적되어 ${ }^{6}$ 저 서생물 등 수생생태계에 악영향을 미칠 수 있다. 최근 국내에서도 하천 및 호소 퇴적물에서 중금속과 유기 염소계화합물을 중심으로 다양한 종류의 오염물질에 대한 실태조사를 수행하고 있으나 브롬화난연제에 대 한 연구는 매우 드문 실정이다.

퇴적물을 대상으로 브롬화난연제 물질의 농도분포 특성을 조사함으로써 발생원을 추정하고 인체와 생태 계에 대한 위해성 평가를 하는데 매우 유용한 정보를 제공할 수 있을 것으로 보인다. 또한 향후 브롬화 난 연제에 의해 야기 될 수 있는 환경오염 문제 등을 사 전에 대비하기 위해 현재 시점에서 다양한 환경매질 에서의 조사가 필요하다.

따라서 본 연구에서는 퇴적물을 대상으로 $\mathrm{PBDEs}$ 와 $\mathrm{HBCD}$ 의 농도분포와 이성질체 분포패턴을 검토하여
이들 물질의 오염특성을 파악하고자 하였다.

\section{2. 연구내용 및 방법}

\section{1. 시료채취 지점선정 및 채취방법}

본 연구에서는 우리나라 주요 하천과 하구언 중에 서 지류의 유입에 의한 영향을 받거나 인근 유역의 토지 이용 등을 고려하여 금강과 낙동강 수계를 중심 으로 채취하였다.

시료채취 지점은 총 11 개로 지점현황과 관련정보를 Fig. 1과 Table 1에 나타내었다. 퇴적물 시료채취는 그 랩형 시료채취기를 이용하였으며, 채취 후 교란되지 않은 부분의 표층에서 깊이 $2 \mathrm{~cm}$ 까지를 표층 퇴적물 로 취하여 $1,000 \mathrm{~mL}$ 용량의 유리병에 담아 저온(-4 $\left.{ }^{\circ} \mathrm{C}\right)$ 에서 보관하였다. 채취시료의 균질성 확보를 위해 지점마다 각각 3 개씩 채취한 후 혼합하여 분석용 시 료로 사용하였다. 퇴적물의 특성상 한 지점에서 퇴적 물 시료를 채취하여도 여러 가지 크기의 다양한 입자 들이 공존할 수 있어 분석하는 과정에서 퇴적물 시료 의 동질성이 최대한 유지되도록 하였다.

\section{2. 분석방법}

퇴적물 시료 중 PBDEs는 USEPA Method 1614에 근 거하여 동위원소희석법과 HRGC/HRMS (HP6890NThermo Finnigan MAT 95XP)를 이용하여 분석하였다. ${ }^{7}$

채취된 시료는 동결건조한 후 $2 \mathrm{~mm}$ 체를 이용하여 협잡물 등을 제거하고 $20 \mathrm{~g}$ 을 속슬렛 원통여지에 넣

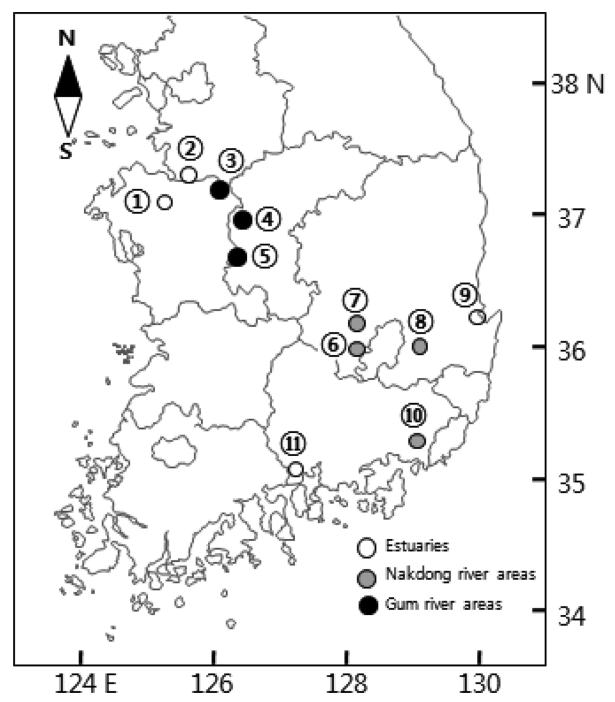

Fig. 1. Sampling sites of this study. 
Table 1. Summary of sampling sites

\begin{tabular}{|c|c|c|c|c|}
\hline ID & Sites & Sampling point & Sample type & Location \\
\hline 3 & \multirow{3}{*}{ Geum river } & Geum river bridge & Clay & $\begin{array}{l}36^{\circ} 28^{\prime} 05.72^{\prime \prime} \mathrm{N} \\
127^{\circ} 07^{\prime} 32.62^{\prime \prime} \mathrm{E}\end{array}$ \\
\hline 4 & & Miho stream & Sand & $\begin{array}{l}36^{\circ} 38^{\prime} 12.41^{\prime \prime} \mathrm{N} \\
127^{\circ} 21^{\prime} 45.10^{\prime \prime} \mathrm{E}\end{array}$ \\
\hline 5 & & Gapcheon down stream & Sand, Clay & $\begin{array}{l}36^{\circ} 26^{\prime} 11.22^{\prime \prime} \mathrm{N} \\
127^{\circ} 23^{\prime} 30.44^{\prime \prime} \mathrm{E}\end{array}$ \\
\hline 6 & \multirow{4}{*}{ Nakdong river } & Dalseong & Sand & $\begin{array}{l}35^{\circ} 42^{\prime} 30.09^{\prime \prime} \mathrm{N} \\
128^{\circ} 25^{\prime} 58.44^{\prime \prime} \mathrm{E}\end{array}$ \\
\hline 7 & & Waegwan bridge & Sand, Clay & $\begin{array}{l}35^{\circ} 59^{\prime} 13.25^{\prime \prime} \mathrm{N} \\
128^{\circ} 23^{\prime} 34.10^{\prime \prime} \mathrm{E}\end{array}$ \\
\hline 8 & & Kumho river & Sand & $\begin{array}{l}35^{\circ} 52^{\prime} 05.12^{\prime \prime} \mathrm{N} \\
128^{\circ} 27^{\prime} 56.03^{\prime \prime} \mathrm{E}\end{array}$ \\
\hline 10 & & West Nakdong down stream & Clay & $\begin{array}{l}35^{\circ} 11^{\prime} 32.02^{\prime \prime} \mathrm{N} \\
128^{\circ} 54^{\prime} 19.39^{\prime \prime} \mathrm{E}\end{array}$ \\
\hline 1 & \multirow{4}{*}{ Estuary } & Anseong stream estuary & Clay & $\begin{array}{l}36^{\circ} 54^{\circ} 58.09^{\prime \prime} \mathrm{N} \\
126^{\circ} 54^{\prime} 48.63^{\prime \prime} \mathrm{E}\end{array}$ \\
\hline 2 & & Sapgyo stream estuary & Clay & $\begin{array}{l}36^{\circ} 51^{\prime} 10.70^{\prime \prime} \mathrm{N} \\
126^{\circ} 51^{\prime} 03.26^{\prime \prime} \mathrm{E}\end{array}$ \\
\hline 9 & & Hyeongsan river estuary & Sand, Clay & $\begin{array}{l}36^{\circ} 01^{\prime} 57.60^{\prime \prime} \mathrm{N} \\
129^{\circ} 22^{\prime} 59.13^{\prime \prime} \mathrm{E}\end{array}$ \\
\hline 11 & & Seomjin river estuary & Clay & $\begin{array}{l}34^{\circ} 57^{\prime} 38.51^{\prime \prime} \mathrm{N} \\
127^{\circ} 46^{\prime} 19.40^{\prime \prime} \mathrm{E}\end{array}$ \\
\hline
\end{tabular}

고 정제용 내부표준물질로 ${ }^{13} \mathrm{C}$-labelled $\mathrm{BDEs}$ 11종을 $1 \sim 5 \mathrm{ng}$ 을 첨가한 다음 $300 \mathrm{~mL}$ 톨루엔으로 16 시간 이 상 추출하였다. 추출액은 약 $2 \mathrm{~mL}$ 까지 농축한 다음 전량을 $\mathrm{n}$-헥산으로 용매전환 후 황산처리를 하였으며 황산처리 후 헥산세정수로 2 3회 세정한 후 $\mathrm{n}$-헥산 층을 탈수하고 감압농축기로 농축하여 다층실리카겔 컬럼(아래서부터 중성-염기성-중성-산성-중성 순으로 충진), 알루미나 컬럼 크로마토그래피 순으로 정제작 업을 수행하였다. 기기분석은 $50 \mu \mathrm{L}$ 까지 농축한 시료 에 실린지 첨가용 내부표준물질로 ${ }^{13} \mathrm{C}$-labelled $\mathrm{BDE}-$ 138 을 $2 \mathrm{ng}$ 첨가하고 DB-5HT $(15 \mathrm{~m} \times 0.25 \mathrm{~mm}$ i.d., $0.1 \mu \mathrm{m}, \mathrm{J} \& \mathrm{~W}$ Scientific) 컬럼을 이용하여 HRGC/ HRMS로 분해능 10,000 이상 $(10 \%$ valley)에서 EISIM(Electron impact-selected ion monitoring)모드로 수행하였다.

$\mathrm{HBCD}$ 분석은 2009년 일본 환경성 종합 환경 정책 국의「화학물질 실태조사 실시 안내」자료를 참고하 였다. 동결 건조된 시료 $2 \mathrm{~g}$ 을 취한 후 추출 전 정제 용 내부 표준물질로 ${ }^{13} \mathrm{C}$-labelled $\alpha-, \beta-, \gamma-\mathrm{HBCD}$ 를 10 $\mathrm{ng}$ 첨가한 후 $\mathrm{PBDEs}$ 와 동일한 조건에서 추출한 후
추출액을 $5 \mathrm{~mL}$ 까지 농축하여 다층 실리카겔 크로마 토그래피로 정제하였다. 정제된 시료는 농축하여 완전 히 건조시킨 후 메탄올로 용매 전환하여 최종 볼륨을 $1 \mathrm{~mL}$ 로 맞추고, 실린지 첨가용 내부표준물질로 $\mathrm{d}_{18}-\gamma$ $\mathrm{HBCD}$ 를 $10 \mathrm{ng}$ 주입하여 LC-MS/MS(Micromass Quattro Ultima triple-quadrupole MS; Micromass, Milford, MA, $\mathrm{USA})$ 로 분석하였다. 기기분석은 $\mathrm{XDB}^{-\mathrm{C}_{18}}$ 컬럼 (3.5 um, $2.1 \mathrm{~mm}$ I.d. $\times 150 \mathrm{~mm}$, ZORBAX Eclipse)을 사 용하여 3 개의 이성체를 분리하였으며 MS/MS 분석은 ESI(Electro spray ionization) 모드에서 MRM (Multiple reaction monitoring)을 사용하여 분석하였다.

\section{3. 정도관리}

실험실에서 사용하는 용매나 실험기구에 의한 방해 물질과 오염여부를 검토하기 위하여 바탕시료를 분석 하였다. PBDEs 분석에 첨가된 11 종의 ${ }^{13} \mathrm{C}$-labelled 이 성질체의 평균 회수율은 45 107\% 범위로 EPA Method 1614 에서 제시한 $25 \sim 150 \%$ 를 만족하였다. 검출한계는 $\mathrm{S} / \mathrm{N}$ 비 3이상으로 하였으며, 각각 동족체별로 mono-에 서 deca-BDEs가 $1 \sim 30 \mathrm{pg} / \mathrm{g}$ 이었다. $\mathrm{HBCD}$ 의 회수율 
은 73 105\% 범위였으며, 방법검출한계는 $\alpha-\mathrm{HBCD}$, $\beta-\mathrm{HBCD}$ 및 $\gamma-\mathrm{HBCD}$ 가 각각 $0.04,0.02,0.08 \mathrm{ng} / \mathrm{g}$ 이 었다.

\section{3. 결과 및 고찰}

\section{1. 퇴적물 중 $\mathrm{PBDEs}$ 농도분포}

퇴적물 시료에서 검출된 PBDEs 농도를 Table 2에 나타내었다.

PBDEs의 총 농도 검출범위는 2.19 101.34 ng/g-dw, 평균농도는 30.70 (중앙값 20.91) ng/g-dw로 나타났다. 이성질체 중 가장 높게 검출된 BDE-209는 1.53 82.60 $\mathrm{ng} / \mathrm{g}-\mathrm{dw}$, 평균농도는 24.49 (중앙값 16.19 ) ng/g-dw으 로 전체 PBDEs의 69.7 89.6\%를 차지하였다.

검출농도를 지점별로 살펴보면 낙동강수계와 금강 수계에서 각각 $3.10 \sim 61.47 \mathrm{ng} / \mathrm{g}-\mathrm{dw}, 2.19 \sim 101.34 \mathrm{ng} / \mathrm{g}-$ $\mathrm{dw}$ 수준으로 검출되었고, 하구언에서는 4.74 26.04 $\mathrm{ng} / \mathrm{g}-\mathrm{dw}$ 이 검출되어 하천이 하구언에 비해 농도변화 가 큰 것으로 나타났다. 상대적으로 높은 농도를 나타 낸 지점은 금강수계의 금강교 $(101.34 \mathrm{ng} / \mathrm{g}-\mathrm{dw})$ 와 미호 천 $(55.50 \mathrm{ng} / \mathrm{g}-\mathrm{dw})$, 낙동강 수계의 금호강 $(61.47 \mathrm{ng} / \mathrm{g}-$ $\mathrm{dw}$ ) 이었다. 금강교 지점은 공주도심을 통과하는 지점 으로 이전에 이 지점의 수질시료에서도 PBDEs 및 $\mathrm{PFOA}$ 가 다른 지점에 비해 고농도로 검출된 바 있으

Table 2. Concentrations of PBDEs and HBCD in sediment

\begin{tabular}{|c|c|c|c|c|c|c|c|c|c|}
\hline \multirow[b]{2}{*}{ ID } & \multirow[b]{2}{*}{ Sampling site } & \multirow{2}{*}{$\begin{array}{l}\text { Ignition } \\
\operatorname{loss}(\%)\end{array}$} & \multicolumn{7}{|c|}{ Concentration (ng/g-dw) } \\
\hline & & & $\begin{array}{c}\text { Mono-nona } \\
\text { BDEs }\end{array}$ & BDE-209 & $\begin{array}{c}\text { total } \\
\text { PBDEs }\end{array}$ & $\alpha-\mathrm{HBCD}$ & $\beta-\mathrm{HBCD}$ & $\gamma-\mathrm{HBCD}$ & $\begin{array}{c}\text { total } \\
\text { HBCD }\end{array}$ \\
\hline 3 & Geum river bridge & 2.85 & 18.75 & 82.60 & 101.34 & 1.64 & 0.45 & 2.24 & 4.32 \\
\hline 4 & Miho stream & 0.30 & 14.11 & 41.39 & 55.50 & 0.04 & 0.02 & 0.09 & 0.15 \\
\hline 5 & Gapcheon down stream & 0.26 & 0.66 & 1.53 & 2.19 & 0.07 & 0.03 & 0.25 & 0.34 \\
\hline 6 & Dalseong & 0.67 & 3.57 & 11.64 & 15.22 & N.D. & N.D. & 0.11 & 0.11 \\
\hline 7 & Waegwan bridge & 0.24 & 1.00 & 2.10 & 3.10 & N.D. & N.D. & N.D. & N.D. \\
\hline 8 & Kumho river & 0.35 & 11.48 & 49.99 & 61.47 & 0.08 & 0.04 & 0.13 & 0.24 \\
\hline 10 & West Nakdong down stream & 2.01 & 6.91 & 30.49 & 37.40 & 0.30 & 0.10 & 0.52 & 0.92 \\
\hline 1 & Anseong stream estuary & 3.37 & 4.57 & 21.48 & 26.04 & 0.34 & 0.16 & 0.76 & 1.26 \\
\hline 2 & Sapgyo stream estuary & 1.51 & 0.96 & 3.78 & 4.74 & 1.91 & 0.47 & 5.47 & 7.85 \\
\hline 9 & Hyeongsan river estuary & 1.21 & 4.72 & 16.19 & 20.91 & N.D. & N.D. & 0.16 & 0.16 \\
\hline \multirow[t]{5}{*}{11} & Seomjin river estuary & 1.88 & 1.57 & 8.19 & 9.76 & 0.10 & 0.04 & 0.71 & 0.84 \\
\hline & Min. & 0.24 & 0.66 & 1.53 & 2.19 & N.D. & N.D. & N.D. & N.D. \\
\hline & Max. & 3.37 & 18.75 & 82.60 & 101.34 & 1.91 & 0.47 & 5.47 & 7.85 \\
\hline & Average & 1.33 & 6.21 & 24.49 & 30.70 & 0.41 & 0.12 & 0.95 & 1.47 \\
\hline & Median & 1.21 & 4.57 & 16.19 & 20.91 & 0.08 & 0.03 & 0.25 & 0.34 \\
\hline
\end{tabular}

Table 3. Comparison of PBDEs levels in sediment with other studies

\begin{tabular}{lccc}
\hline \hline \multicolumn{1}{c}{ Location } & $\begin{array}{c}\text { BDE-209 } \\
\text { (ng/g-dw) }\end{array}$ & $\begin{array}{c}\text { Total PBDEs } \\
\text { (ng/g-dw) }\end{array}$ & Ref. No. \\
\hline This Study & $1.53 \sim 82.60$ & $2.19 \sim 101.34$ & - \\
Nakdong River (Korea) & $0.39 \sim 190$ & $0.55 \sim 300.00$ & 10 \\
Masan Bay (Korea) & $2.33 \sim 64.2$ & $3.05 \sim 72.45$ & 11 \\
Coast water (Korea) & $0.35 \sim 98.0$ & $0.4 \sim 130.00$ & 12 \\
Great Lakes (USA) & $6.6 \sim 242.0$ & $7.09 \sim 248.30$ & 13 \\
Tokyo Bay (Japan) & $0.89 \sim 85.0$ & $0.941 \sim 88.60$ & 14 \\
Spanish coast (Spain) & $2.46 \sim 132.0$ & $2.7 \sim 133.90$ & 16 \\
Scheldt estuary (Netherland) & $240 \sim 1,700$ & $254 \sim 1,722$ & 17 \\
Peal river estuary (China) & $0.41 \sim 7,341$ & $0 \sim 7,436$ & 15 \\
Beijiang River (China) & $0.23 \sim 103.0$ & $0.249 \sim 103.91$ & 15 \\
Yangtz River (China) & $0.16 \sim 95.0$ & $0.16 \sim 95.55$ & \\
\hline
\end{tabular}


나 $^{8}$ 구체적인 발생원과 오염경로에 대해서는 추가적 인 조사가 필요하다. 금호강은 PBDEs를 난연제로 사 용하는 섬유, 플라스틱, 자동차 등의 제조업체가 주변 공단에 위치해 있어 하천수가 유입되는 지역의 토지 이용 특성이 퇴적물 중 $\mathrm{PBDEs}$ 검출농도와 관련이 있 는 것으로 판단된다.

본 연구에서 검출된 퇴적물 내 $\mathrm{PBDEs}$ 농도수준을 국내 · 외에서 보고된 결과와 비교하여 Table 3에 나타 내었다.

본 연구결과를 국내에서 보고된 기존 자료와 비교 하여 살펴보면 낙동강 표층 퇴적물 중 $\mathrm{PBDEs}$ 농도는 0.55 300 ng/g-dw, ${ }^{9}$ 마산만 표층에서는 3.05 72.45 ng/ $\mathrm{g}-\mathrm{dw},{ }^{10}$ 국내 주요연안 연안에서는 $0.4 \sim 130 \mathrm{ng} / \mathrm{g}^{-\mathrm{dw}^{11}}$ 으로 본 연구결과와 유사한 농도 범위를 나타내었다.

외국자료와 비교하면 PBDEs 농도범위는 미국 오대 호 $(52.03 \sim 246.85 \mathrm{ng} / \mathrm{g}-\mathrm{dw})^{12}$ 에 비해 낮은 수준이었고, 일본 동경만(0.9 88.6 ng/g-dw), ${ }^{13}$ 스페인 연안(2.7 133.9 $\mathrm{ng} / \mathrm{g}-\mathrm{dw})^{14}$ 그리고 중국 양쯔강 $(0.16 \sim 99.55 \mathrm{ng} / \mathrm{g}-\mathrm{dw})^{15}$ 과 유사하였다. 한편, 외국의 연구결과는 분석대상 이성 질체 수가 조사 시기에 따라 조금씩 달라 정확한 비 교가 어려우나 네덜란드 $(240 \sim 1,700 \mathrm{ng} / \mathrm{g}-\mathrm{dw})^{16}$ 와 중국 진주강 $(0.41 \sim 7,341 \mathrm{ng} / \mathrm{g}-\mathrm{dw})^{17}$ 등 오염원 주변에서 보 고된 BDE-209 농도는 다양한 농도수준을 보이고 있 으며, 공통적으로 $\mathrm{BDE}-209$ 가 총 $\mathrm{PBDEs}$ 의 대부분을 차지하는 것으로 나타났다.

\section{2. 퇴적물 중 $\mathrm{HBCD}$ 농도분포}

퇴적물 시료 중 샘플 중 $\mathrm{HBCD}$ 분석 결과를 Table 2에 나타내었다.

총 11 개 시료에서 검출된 $\mathrm{HBCD}$ 농도범위는 N.D. $7.85 \mathrm{ng} / \mathrm{g}-\mathrm{dw}$, 평균농도는 1.47 (중앙값 0.34 ) ng/g-dw 로 나타났다.

퇴적물에서 검출된 $\mathrm{HBCD}$ 농도는 $\mathrm{PBDEs}$ 농도에 비해 약 $1 / 20$ 정도 낮은 범위로서 이와 같은 결과는 국내에서 사용된 브롬화 난연제 중 $\mathrm{HBCD}$ 사용량이 상대적으로 적었기 때문인 것으로 판단된다. 가장 높 은 농도는 삽교천 하구언으로 이 지역 주변은 자동차 와 전자산업 관련공장이 위치해 있는 곳이었으며, 금 강교 지점도 상대적으로 높은 농도(4.32 ng/g-dw)가 검출되었는데 이 지점은 $\mathrm{PBDEs}$ 가 최고농도로 검출된 지점으로 주변지역에 브롬화난연제 배출원이 존재할 가능성이 있어 이에 대한 조사가 추가적으로 이루어 져야 할 것으로 판단된다.

본 연구에서 검출된 농도 분포를 기존 연구와 비교
Table 4. Comparison of HBCD levels in sediment with other studies

\begin{tabular}{lcc}
\hline \hline \multicolumn{1}{c}{ Location } & $\begin{array}{c}\text { HBCD } \\
\text { (ng/g-dw) }\end{array}$ & Ref. No. \\
\hline This Study & N.D. 7.85 & - \\
Coast water (Korea) & $0.39 \sim 59$ & 10 \\
Nakdong River (Korea) & $0.11 \sim 19$ & 11 \\
Detroit River (USA) & $0.075 \sim 3.7$ & 18 \\
Lake sediment (UK) & $0.88 \sim 4.8$ & 19 \\
Tokyo Bay (Japan) & $0.056 \sim 2.3$ & 13 \\
River sediment (Germany) & $0.99 \sim 19.79$ & 22 \\
Scheldt estuary (Netherland) & $0.7 \sim 99$ & 16 \\
River sediment (China) & $0.0 \sim 206$ & 23 \\
River sediment (Japan) & $0.8 \sim 2,057$ & 20 \\
Cinca River (Spain) & $90 \sim 2,430$ & 21 \\
\hline
\end{tabular}

하여 Table 4에 나타내었다.

본 연구결과는 우리나라 주요 연안 퇴적물 시료에 서 검출된 농도 $(0.39 \sim 59 \mathrm{ng} / \mathrm{g}-\mathrm{dw})^{10}$ 및 낙동강 $(0.11 \sim 19$ $\mathrm{ng} / \mathrm{g}-\mathrm{dw})^{11}$ 보다는 다소 낮았으며, 미국 디트로이트 하 천(0.075 3.7 ng/g-dw)이나, ${ }^{18}$ 영국의 호소(0.88 4.8 $\mathrm{ng} / \mathrm{g}-\mathrm{dw})^{19}$ 및 일본 쯔루미 $(0.8 \sim 4.8 \mathrm{ng} / \mathrm{g}-\mathrm{dw})^{20}$ 강과 동 경만 $(0.056 \sim 2.3 \mathrm{ng} / \mathrm{g}-\mathrm{dw})^{13}$ 등 오염원의 영향을 직접적 으로 받지 않는 지역을 대상으로 수행한 농도분포와 유사한 범위를 나타내었다. 반면 $\mathrm{HBCD}$ 를 직접 생산 하거나 공업적으로 사용하는 지역 주변하천 퇴적물 $(90 \sim 2,430 \mathrm{ng} / \mathrm{g}-\mathrm{dw})^{20}$ 과 섬유단지 폐수가 유입되는 하 천 $(0.8 \sim 2,570 \mathrm{ng} / \mathrm{g}-\mathrm{dw})^{21}$ 등 오염원과 직접적인 관련이 있는 지역의 퇴적물에서 검출된 최고농도에 비하면 1/ 300 정도로 매우 낮은 수준이다.

$\mathrm{HBCD}$ 는 2001년에 세계적으로 약 17,000톤이 사 용되었으며 이중 $23 \%$ 가 아시아에서 소비되었고 우리 나라도 주요 소비국으로 알려져 있다. 그러나 본 연구 에서 검출된 하천 퇴적물 중 $\mathrm{HBCD}$ 농도는 외국에서 보고된 농도범위와 유사한 수준으로 관찰되었다. 이러 한 결과는 우리나라 하천 퇴적물 특성과 2008년부터 시행된 4대 강 준설 등의 영향을 받았을 가능성이 있 다. 그러나 국내 퇴적물 $\mathrm{HBCD}$ 의 농도 분포에 대해서 는 조사된 자료가 제한적이기 때문에 향후 분해산물 을 포함한 폭넓은 연구가 추가적으로 수행되어야 할 것으로 보인다.

\section{3. 퇴적물 중 $\mathrm{PBDEs}$ 이성질체 분포특성}

퇴적물에서 검출된 $\mathrm{PBDEs}$ 이성질체 분포를 Fig. 2 에 나타내었다. 


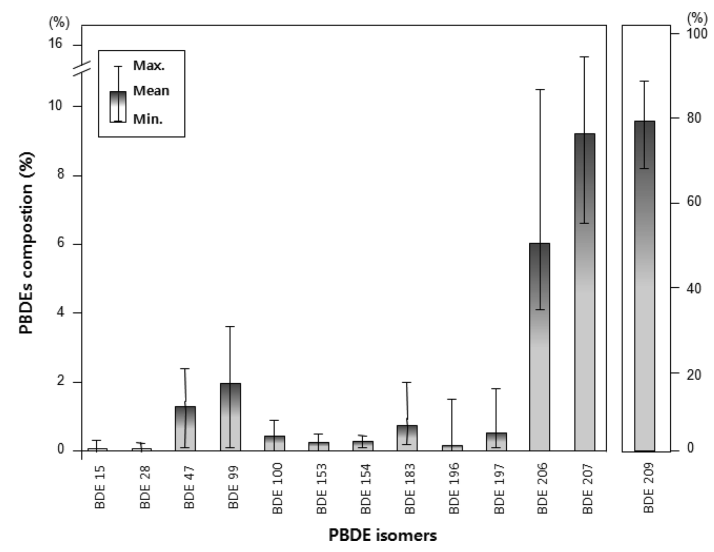

Fig. 2 Isomer distribution ratio of PBDEs in sediments.

전체 이성질체 중 $\mathrm{BDE}-209$ 가 67.8 89.6\%의 범위로 가장 높은 구성비를 나타내었으며 이러한 경향은 전 세계 다양한 지역의 퇴적물뿐만 아니라 환경시료에서 도 관찰되는 일반적인 결과이다. ${ }^{14-15} \mathrm{BDE}-209$ 제외한 21 개 $\mathrm{PBDE}$ 이성질체 중 $\mathrm{BDE}-207(9.4 \%)$ 이 가장 높 은 구성비를 보였으며, 다음으로 $\mathrm{BDE}-206(6.2 \%)$, BDE-99 (2.0\%), BDE-47 (1.3\%) 순으로 대부분의 퇴적 물에서 유사한 경향을 나타내었다.

상업용 제품인 deca-BDE (Bromkal 82-0DE와 Saytex $102 \mathrm{E})$ 는 BDE-209 이성질체를 $90 \%$ 이상 함유하고 있 으며 우리나라에서 2004년에 약 17,000 톤을 사용하여 최고치에 도달한 후 2008년에 4,000톤으로 감소하였 으나 지금도 여전히 사용하고 있다. ${ }^{24}$ 따라서 퇴적물 에서 가장 높은 비율을 나타낸 BDE-209는 제품 사용 량과 직접적인 관계가 있는 것으로 판단된다.

상업용 penta-BDE와 octa-BDE는 2006년부터 취급 제한물질로 지정되어 제조, 수입, 사용 등을 금지하였 다. 상업용 penta-BDE 제품(DE-71, Bromkal 70-5DE) 에는 $\mathrm{BDE}-47$ 과 $\mathrm{BDE}-99$ 가 약 $70 \%$ 이상을 차지하고 있으며 이들 비율은 약 0.8 에서 1.1 사이를 이루고 있 다. ${ }^{25}$ 퇴적물에서 검출된 $\mathrm{BDE}-47$ 과 $\mathrm{BDE}-99$ 비율은 0.4 에서 1.0 (평균 0.7)사이로 모든 시료에서 BDE-99 가 높게 검출되었다. BDE-209 다음으로 높게 검출된 $\mathrm{BDE}-207$ 과 $\mathrm{BDE}-206$ 은 상업용 $\mathrm{PBDEs}$ 중 octa-BDE 와 deca-BDE의 주요 구성성분이다. 따라서 이들 이성 질체도 제품 사용에 의한 것으로 판단된다. 한편, di$\mathrm{BDE}$ 와 tri-BDE 등 저브롬계 이성질체는 모든 지점에 서 매우 낮은 비율을 나타냈다.

BDE-209 이성질체를 비롯하여 BDE-47, BDE-99, BDE-206 및 BDE-207 등 퇴적물 내에서 검출된 주요
이성질체는 $\mathrm{PBDE}$ 상업용 제품 사용에 의한 직접 배 출이 기여하였을 것으로 판단된다. 또한 낮은 분포를 나타낸 BDE- $15, \mathrm{BDE}-28$ 과 같은 저브롬계 이성질체는 이들 물질이 미량으로 함유된 상업용 제품의 사용과 고브롬계 $\mathrm{PBDEs}$ 의 광학적 분해나 생물학적 분해 등에 의한 탈 브롬화 작용 등에 의한 것으로 추정된다. ${ }^{30}$

이와 같이 퇴적물 시료에서 검출되는 $\mathrm{PBDEs}$ 이성 질체 분포는 제품 사용에 의한 유출과 같은 직접적인 원인 이외에도 $\log \mathrm{K}_{\mathrm{ow}}$ 와 같은 제품의 물리화학적 성 질과 광학적 분해 및 환경 중 거동 특성 등이 복합적 으로 작용하여 분포패턴에 영향을 미치는 것으로 설 명할 수 있다.

\section{4. 퇴적물 중 $\mathrm{HBCD}$ 이성질체 분포특성}

퇴적물에서 검출된 $\mathrm{HBCD}$ 이성질체 분포를 Fig. 3에 나타내었다.

본 연구에서 조사한 퇴적물 시료 중 불검출된 1 개 지점을 제외하고 10 개 지점의 $\mathrm{HBCD}$ 이성질체 분포 특성을 살펴보면 $\alpha-\mathrm{HBCD}, \beta-\mathrm{HBCD}$ 및 $\gamma-\mathrm{HBCD}$ 의 비율이 각각 $0 \sim 37.9 \%, 0 \sim 14.2 \%, 51.8 \sim 100 \%$ 의 범위로 나타났다. 퇴적물에서 $\gamma-\mathrm{HBCD}$ 가 주요 이성질체로 검 출된 것은 기존의 국내외 퇴적물 연구결과에서 보고 된 경향과 유사하였다. 일반적으로 상업용으로 합성된 $\mathrm{HBCD}$ 중 $\gamma-\mathrm{HBCD}$ 의 비율은 $75 \sim 89 \%$ 를 차지하고 $\alpha-$ $\operatorname{HBCD}(10 \sim 13 \%)$ 와 $\beta-\mathrm{HBCD}(1 \sim 12 \%)$ 는 비율이 매우 낮은 것으로 알려져 있다. ${ }^{26}$ 본 연구의 퇴적물 시료에 서 검출된 $\alpha-\mathrm{HBCD}, \beta-\mathrm{HBCD}$ 의 비율은 상업용 제품 에 함유된 비율보다 높게 나타났는데 이는 $\mathrm{HBCD}$ 의

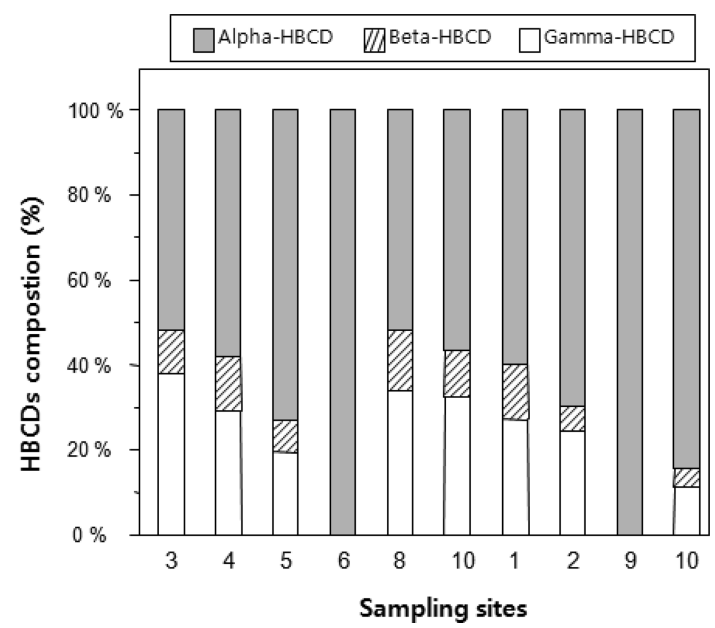

Fig. 3. Isomer distribution ratio of $\mathrm{HBCD}$ in sediments. 
제조나 사용과정에 따라 구성 비율이 달라지거나 수 계에서 선택적인 이성질체 변화가 일어나는 것으로 판단된다.

$\gamma-\mathrm{HBCD}$ 는 $160{ }^{\circ} \mathrm{C}$ 이상의 온도에서 열을 가할 경우 $\alpha-\mathrm{HBCD}$ 로 이성질체 변형이 일어나는 것으로 알려져 있으며 열처리한 제품에서 검출된 $\mathrm{HBCD}$ 의 이성질체 는 $\alpha-\mathrm{HBCD}$ 가 $78 \%$ 로서 가장 우세하다. ${ }^{27}$ 또한 Gerecke 등은 ${ }^{28}$ 혐기성 조건하에서 $\alpha-\mathrm{HBCD}$ 에 비해 $\beta-\mathrm{HBCD}$ 와 $\gamma-\mathrm{HBCD}$ 가 쉽게 분해되는 것으로 보고하고 있어 퇴적물 내로 유입된 $\gamma-\mathrm{HBCD}$ 가 혐기성 조건하에서 분 해가 진행되었을 가능성도 있다.

이 외에도 $\mathrm{HBCD}$ 의 이성질체별 증기압은 $\gamma<\beta<\alpha$ 순이며 특히 $\alpha-\mathrm{HBCD}$ 증기압은 $\gamma-\mathrm{HBCD}$ 증기압보다 10 배 이상 크기 때문에 이들 물질이 함유된 제품 사 용시 $\alpha-\mathrm{HBCD}$ 의 환경 중 배출이 쉽게 일어나는 것으 로 보고되고 있다. ${ }^{29}$ 따라서 환경 중 거동에 영향을 미치는 물리화학적 특성도 퇴적물 중 $\mathrm{HBCD}$ 의 이성 질체 분포에 영향을 미치는 중요한 요소인 것으로 보 인다.

이상과 같이 퇴적물에서 검출되는 $\mathrm{HBCD}$ 의 이성질 체 패턴이 상업용으로 제조된 제품 패턴과 다른 것은 $\mathrm{HBCD}$ 의 제조와 사용에 따른 열적변화에 의한 영향 과 이성질체별로 다른 물리화학적 성질과 환경 중에 서 일어나는 다양한 특성이 복합적으로 작용한 것으 로 판단된다.

\section{4. 결 론}

퇴적물 중 브롬화난연제인 $\mathrm{PBDEs}$ 와 $\mathrm{HBCD}$ 의 잔류 농도 분포특성에 대해 검토하여 얻어진 결론을 정리 하면 다음과 같다.

1. 퇴적물 중 PBDEs의 총 농도 검출범위는 2.19 $101.34 \mathrm{ng} / \mathrm{g}-\mathrm{dw}$, 평균농도는 $30.70 \mathrm{ng} / \mathrm{g}-\mathrm{dw}$ 로 나타났 으며 현재까지 사용 중인 BDE-209의 농도수준은 1.53 82.60 (평균 24.76) ng/g-dw로 전체 PBDEs의 $69.789 .6 \%$ 를 차지하였다. $\mathrm{HBCD}$ 농도범위는 N.D. 7.85(평균 1.47) ng/g-dw로 PBDEs에 비해 약 $1 / 20$ 정 도 낮은 범위로 검출되었으며 이는 국내에서의 실제 사용량과 관련된 것으로 판단된다. 퇴적 물 중 브롬화 난연제 검출수준은 외국에서 보고된 특정 발생원 주 변지역을 제외한 대부분 국가의 하천 및 연안 퇴적물 중 농도범위와 유사하였다.

2. PBDEs의 이성질체 패턴 분석결과, BDE-209 이 성질체를 비롯하여 BDE-47, BDE-99, BDE-206 및
BDE-207 등 퇴적물 내에서 검출된 주요 이성질체는 $\mathrm{PBDE}$ 상업용 제품 사용에 의한 직접 배출이 기여하 였을 것으로 판단되며, 낮은 비율로 검출된 $\mathrm{BDE}-15$, $\mathrm{BDE}-28$ 과 같은 저브롬계 이성질체는 미량으로 함유 된 상업용 제품의 사용과 동시에 고브롬계 $\mathrm{PBDEs}$ 의 광학적 분해나 생물학적 분해 등에 의한 탈 브롬화 작용 등에 의한 것으로 추정된다.

3. 퇴적물에서 검출된 $\mathrm{HBCD}$ 의 이성질체 분포는 $\alpha$ $\mathrm{HBCD}$ 의 비율이 최대 $37.9 \%$ 로 나타나 상업용 제품에 함유된 비율(10 13\%)보다 높게 나타났다. 이는 상업 용 제품에 $75 \sim 89 \%$ 정도로 포함된 $\gamma-\mathrm{HBCD}$ 가 제품의 제조나 사용 과정에서 열적처리 등에 의해 $\alpha-\mathrm{HBCD}$ 로 선택적인 이성질체 변화가 일어날 수 있으며, 또한 $\alpha-\mathrm{HBCD}$ 가 혐기성 조건에서 $\alpha-\mathrm{HBCD}$ 에 비해 상대적 으로 쉽게 분해되는 것이 퇴적물에서 이성질체 분포 변화에 영향을 미치는 원인인 것으로 판단된다.

\section{참고문헌}

1. Cheri Peele, 'Washington state PBDE chemical action plan', Washington state department of ecology, 17-20, 2004.

2. Ann Blake, $\mathrm{Ph}, \mathrm{D}$, The next generation of POPs : PBDEs and Lindane, International POPs Elimination Network, 3, 2005.

3. K. Nylund, L. Asplund, B. Janssen, P. Jonsson, K. Litzen and U. Sellström, Chemosphere, 24, 1721-1730 (1992).

4. N. H. Minh, Y. Isobe, D. Ueno, K. Matsumoto, M. Mine, N. Kajiwara, S. Takahashi and S. Tanabe, Environ. Pollution., 148, 409-417 (2007).

5. D. Meironyté, Å. Bergman and K. Norén, Arch. Environ. Contam. Toxicol., 40, 564-570 (2001).

6. Korea Environment Institite, 'Management of contaminated sediments from lake and river', 1998.

7. Environment Ministry of Japan, 'Information on survey of chemicals', 2009.

8. National Institute of Environmental Research, 'Survey on temporal and spatial distribution in environment of NEW POPs(II)', 2011.

9. H.-H. Kang, 'Spatial distribution of brominated flame retardants in surface sediment of the Nakdong River in Korea Domestic' Master Thesis, Busan National University, 2011.

10. S. U. We, J. H. Yoon and N. W. Min, Environ. Eng. Res., 
32(5), 427-436 (2010).

11. K. Ramu, T. Isobe, S. Takahashi, E.-Y. Kim, B.-Y. Min and S-U We, Chemosphere, 79(7), 713-719 (2010).

12. W. Song, A. Li, J. C. Ford, N. C. Sturchio, K. J. Rockne, D. R. Buckley and W. J. Mills, Environ. Sci. Technol., 39, 5600-5605 (2005).

13. N. H. Minh, T. Isobe, D. Ueno, K. Matsumoto, M. Mine, N. Kajiwara, S. Takahashi and S. Tanabe, Environ. Pollut., 148, 409-17 (2007).

14. E. Eljarrat, D. Larrazabal, B. Fabrellas, A. R. Fernandez-Alba, F. Borrull, R. M. Marce and D. Barcelo, Environ. Pollut., 136(3), 493-501 (2005).

15. S. J. Chen, X. J. Gao, B. X. Mai, Z. M. Chen, X. J. Luo, G. Y. Sheng, J. M. Fu and E. Y. Zeng, Environ. Pollut., 144, 951-957 (2006).

16. T. A. Verslycke, A. D. Vethaak, K. Arijs and C. R. Janssen, Environ. Pollut., 136, 19-31 (2005).

17. B. X. Mai, S. J. Chen, X. J. Luo, L. G. Chen, Q.S. Yang, G. Y. Peng, J. M. Fu and E. Y. Zeng, Environ. Sci. Technol., 39, 3521-3527 (2005).

18. C. H. Marvin, G. T. Tomy, M. Alaee and G. Macinnis, Chemosphere, 64(2), 268-759 (2006).

19. H. Stuart, A. A Mohamed, L. R. Neil, D. Simon and T. A. Davidson, Environ. Sci. Technol, 43(24), 9077-9083 (2009).

20. P. Guerra, A. De La Cala, G. Marsha, E. Eljarrata and
D. Barceló, J. Hydrol., 369, 360-367 (2009).

21. S. Managaki, I. Enomoto and S. Masunaga, Environ Monitor, 14(3), 901-977 (2012).

22. S. Thorsten, K. Andrea, R. Matthias, S. George, W.-S. Evelyn and L. Peter, Organohalogen Compounds, 70, 1590-1593 (2008)

23. H. Li, H. Shang, P. Wang, Y. Wang, H. Zhang, Q. Zhang and G. Jiang. J. Environ. Sci., 24, in press (2012).

24. Cischem, 'Status report on domestic and foreign markets, and environmental regulations of BFRs', 2009.

25. MARK J. LA GUARDIA, ROBERT C. HALE and ELLEN HARVEY., Environ. Sci. Technol, 40, 62476254 (2006).

26. V. H. Norbert, W. B. Schweiz, M. Kohler and A. C. Gerecke, Chemosphere, 61, 65-73 (2005).

27. M. Peled, R. Scharia and D. Sondack, In 'Advances in Organobromine Chemistry II', p.92-99, Elsevier, Amsterdam, 1995.

28. A. C. Gerecke, W. Giger, P. C. Hartmann, N. V. Heeb, H. E. Kohler, P. Schmid, M. Zennegg and M. Kohler, Chemosphere, 64, 311-317 (2006).

29. Environment Ministry of Japan, Studies on Material Cycles and Waste Management, 2011.

30. Juan Bezares-Cruz, Chadt. Jafvert and Inezhua, Environ. Sci. Technol. 38, 4149-4156 (2004). 